\title{
FOCUS
}

\section{China Launched the First Wastewater Resource Recovery Factory in Yixing}

\author{
Jiuhui Qu (ه) $)^{1,8}$, Hongqiang Ren ${ }^{2,8}$, Hongchen Wang ${ }^{3,8}$, Kaijun Wang $^{1,8}$, Gang Yu ${ }^{1,8}$, Bing Ke ${ }^{4,8}$, Han-Qing Yu ${ }^{5,8}$, \\ Xingcan Zheng ${ }^{6,8}, \mathrm{Ji} \mathrm{Li}^{7,8}$ \\ 1 School of Environment, Tsinghua University, Beijing 100084, China \\ 2 School of the Environment, Nanjing University, Nanjing 212013, China \\ 3 School of Environment and Nature Resources, Renmin University of China, Beijing 100872, China \\ 4 Administrative Centre for China's Agenda 21, Ministry of Science and Technology, Beijing 100038, China \\ 5 CAS Key Laboratory of Urban Pollutant Conversion, University of Science \& Technology of China, Hefei 230026, China \\ 6 North China Municipal Engineering Design \& Research Institute, Tianjin 300074, China \\ 7 School of Environment and Civil Engineering, Jiangnan University, Wuxi 214122, China \\ 8 Expert Committee for China's Concept WWTPs, Beijing 100044, China
}

(C) Higher Education Press 2021

On October 18th 2021, the inaugural ceremony for the first wastewater resource recovery factory (WRRF) in China, Yixing Concept WRRF (Fig. 1), was held in the Environmental Science Park, Yixing, Jiangsu Province (Li, 2021). It is a milestone for water pollution control, which opens a new chapter for sustainable wastewater management.
China has the world's largest and still growing wastewater sector, thus its progress and experience in technology and mode is very valuable to the rest of the world. Over last decades, the unique rapid development of China has forged its leading position in wastewater treatment capacity and technology innovation capability $(\mathrm{Qu}$ et al., 2019). In 2014, a few well-known Chinese environmental

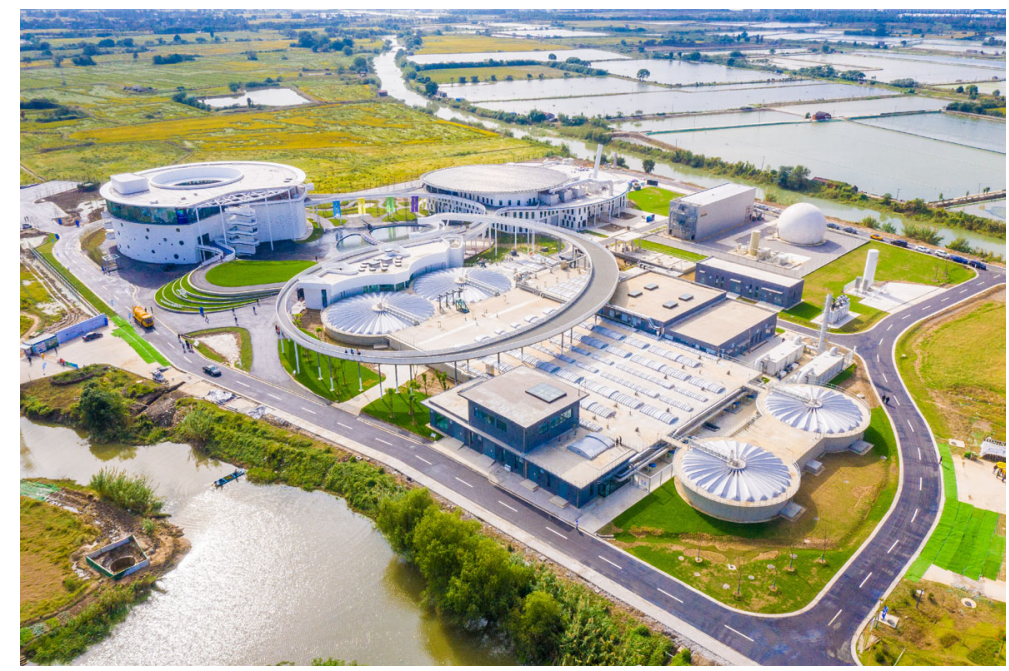

Fig. 1 The aerial view of Yixing Concept Wastewater Resource Recovery Factory.

Received October 20, 2021; Accepted October 20, 2021; Available online October 30, 2021

E-mail: jhqu@tsinghua.edu.cn

Special issue-Visions 
experts led by Prof. Jiuhui $\mathrm{Qu}$, member of Chinese Academy of Engineering, established the Expert Committee of China Concept Plant for Wastewater Treatment, and proposed the vision of "constructing futureoriented China Concept Plants for Wastewater Treatment" (Qu et al., 2014). After a few years' systematic investigation and 18 months' construction, this first wastewater resource recovery factory, Yixing Concept WRRF is officially in operation now.

Yixing Concept WRRF is an integral center for water purification, organic matter co-treatment, and production scale research and development. It is an ecological complex that overturned the appearance of traditional wastewater treatment plant, while transformed the pollution reduction plant into water, energy, and fertilizer factory. The launch of Yixing Concept WWRF will not only promote the new concept that "wastewater is resource, wastewater treatment plant is a resource factory", but also redefine the relation between city and wastewater treatment plant, which integrated ecology, life, and work in the newly created and public shared space in the coming years.

\section{References}

Li Z (2021). Yixing concept wastewater resource recovery factory constructed and operated. People's Daily, 2021-10-18. https:/wap. peopleapp.com/article/rmh24140020/rmh24140020 (in Chinese, Accessed October 20, 2021)

Qu J, Wang K, Wang H, Yu G, Ke B, Yu H (2014). Constructing futureoriented wastewater treatment concept plant. China Environment News, 2014-01-07: 010 (in Chinese)

Qu J, Wang H, Wang K, Yu G, Ke B, Yu H Q, Ren H, Zheng X, Li J, Li W W, Gao S, Gong H (2019). Municipal wastewater treatment in China: Development history and future perspectives. Frontiers of Environmental Science \& Engineering, 13 (6): 88 